\title{
PROPERTIES OF EXTERNAL PLEXIFORM LAYER INTERNEURONS IN MOUSE OLFACTORY BULB SLICES
}

\author{
K. A. HAMILTON, ${ }^{a *}$ T. HEINBOCKEL, ${ }^{b 1}$ M. ENNIS, ${ }^{b 1}$ \\ G. SZABÓ, ${ }^{c}$ F. ERDÉLYI ${ }^{c}$ AND A. HAYAR ${ }^{\mathrm{b} 1}$ \\ ${ }^{a}$ Department of Cellular Biology and Anatomy, Louisiana State Uni- \\ versity Health Sciences Center, 1501 Kings Highway, Shreveport, LA \\ 71130-3932, USA \\ ${ }^{b}$ Department of Anatomy and Neurobiology and Program in Neuro- \\ science, University of Maryland, Baltimore, MD 21201, USA \\ ${ }^{c}$ Department of Gene Technology and Developmental Neurobiology, \\ Institute of Experimental Medicine, $\mathrm{H}-1450$, Budapest, Hungary
}

\begin{abstract}
In the external plexiform layer (EPL) of the main olfactory bulb, apical dendrites of inhibitory granule cells form large numbers of synapses with mitral and tufted $(M / T)$ cells, which regulate the spread of activity along the $M / T$ cell dendrites. The EPL also contains intrinsic interneurons, the functions of which are unknown. In the present study, recordings were obtained from cell bodies in the EPL of mouse olfactory bulb slices. Biocytin-filling confirmed that the recorded cells included interneurons, tufted cells, and astrocytes. The interneurons had fine, varicose dendrites, and those located superficially bridged the EPL space below several adjacent glomeruli. Interneuron activity was characterized by high frequency spontaneous excitatory postsynaptic potential/currents that were blocked by the $\alpha$-amino-3hydroxy-5-methylisoxazole-4-propionic acid (AMPA)/kainate receptor antagonist 6-cyano-7-nitroquinoxaline-2,3-dione and largely eliminated by the voltage-sensitive $\mathrm{Na}^{+}$channel blocker, tetrodotoxin. Interneuron activity differed markedly from that of tufted cells, which usually exhibited spontaneous action potential bursts. The interneurons produced few action potentials spontaneously, but often produced them in response to depolarization and/or olfactory nerve (ON) stimulation. The responses to depolarization resembled responses of late- and fast-spiking interneurons found in other cortical regions. The latency and variability of the ON-evoked responses were indicative of polysynaptic input. Interneurons expressing green fluorescent protein under control of the mouse glutamic acid decarboxylase 65 promoter exhibited identical properties, providing evidence that the EPL interneurons are GABAergic. Together, these results suggest that EPL interneurons are excited by M/T cells via AMPA/ kainate receptors and may in turn inhibit $M / T$ cells within spatial domains that are topographically related to several
\end{abstract}

${ }^{1}$ Present address: Department of Anatomy, Howard University College of Medicine, Washington, DC 20059, USA (T. Heinbockel); Department of Anatomy and Neurobiology, University of Tennessee Health Science Center, Memphis, TN 38163, USA (M. Ennis, A. Hayar).

*Corresponding author. Tel: +1-318-675-5391; fax: +1-318-675-5889.

E-mail address: khamil@lsuhsc.edu (K. A. Hamilton).

Abbreviations: ACSF, artificial cerebrospinal fluid; AMPA, $\alpha$-amino3-hydroxy-5-methylisoxazole-4-propionic acid; CNQX, 6-cyano-7nitroquinoxaline-2,3-dione; EPL, external plexiform layer; EPSP/C, excitatory postsynaptic potential/current; ET, external tufted; GAD, glutamic acid decarboxylase; GFP, green fluorescent protein; GL, glomerular layer; GluR1, glutamate receptor 1; IR, immunoreactive; $\mathrm{MCL}$, mitral cell layer; $\mathrm{M} / \mathrm{T}$, mitral/tufted; ON, olfactory nerve; PG, periglomerular; SA, short axon; TTX, tetrodotoxin; VG, Van Gehuchten.

$0306-4522 / 05 \$ 30.00+0.00$ C 2005 Published by Elsevier Ltd on behalf of IBRO. doi:10.1016/j.neuroscience.2005.03.008 adjacent glomeruli. (c 2005 Published by Elsevier Ltd on behalf of IBRO.

Key words: AMPA, GABAergic inhibition, fast-spiking interneurons, high-frequency EPSP/EPSCs, autocorrelation, glomerular coding.

The external plexiform layer (EPL) of the olfactory bulb is the second level of synaptic processing in olfaction. This layer lies immediately below the glomeruli, where the axons of the olfactory nerve (ON) converge onto the dendrites of mitral and tufted $(\mathrm{M} / \mathrm{T})$ cells and periglomerular (PG) cells. The EPL primarily consists of a dense neuropil formed by the $M / T$ cell dendrites and GABAergic granule cell dendrites, which ascend into the EPL from the deeper, mitral cell and granule cell layers, respectively. Within the $E P L$, the lateral dendrites of the M/T cells form large numbers of type 1 (ultrastructurally excitatory) synapses with the granule cell dendrites, which return type 2 (ultrastructurally inhibitory) synapses, $\sim 80 \%$ of which are paired (Price and Powell, 1970; reviewed in Shepherd et al., 2004). The GABAergic synapses of the EPL have been shown to provide robust, feedback inhibition (see Jahr and Nicoll, 1982) and lateral inhibition (Isaacson and Strowbridge, 1998; Margrie et al., 2001; Lowe, 2002; Xiong and Chen, 2002) of M/T cells. Together with A-type $\mathrm{K}^{+}$currents (Christie and Westbrook, 2003), this inhibition regulates the spread of backpropagating action potentials along the $\mathrm{M} / \mathrm{T}$ cell lateral dendrites, which can extend up to $\sim 1 \mathrm{~mm}$ from the cell body (Mori et al., 1983).

In addition to the granule cells, the olfactory bulb contains a variety of other interneurons. The most numerous are the PG cells, which are a heterogeneous cell population (see Kosaka et al., 1998). Many of the PG cells are GABAergic, however, and they appear to inhibit M/T cells at the first level of synaptic processing in the glomerular layer (GL) (Getchell and Shepherd, 1975; Duchamp-Viret et al., 1993). The inhibition can be local, within a glomerulus (Urban and Sakmann, 2002), or disynaptically mediated via short axon (SA) cells over distances of up to 20-30 glomeruli (Aungst et al., 2003).

In comparison with the other olfactory bulb layers, the EPL has few cell bodies. In the rat and hamster, which have been most thoroughly studied, it nevertheless contains significant numbers of interneurons (Schneider and Macrides, 1978; Kosaka et al., 1994), tufted cells of several types (Macrides and Schneider, 1982), and astrocytes (Bailey and Shipley, 1993; Mirich et al., 2002). Electrophysiological recordings have shown that the responses of different $\mathrm{M} / \mathrm{T}$ cell types to $\mathrm{ON}$ stimulation are correlated 
with the depth of the lateral dendrites in the EPL (Ezeh et al., 1993). No comparable recordings have been obtained from the interneurons of the EPL, the electrophysiological properties and functions of which are unknown.

The EPL interneurons are multipolar neurons that were originally described in the cat by Van Gehuchten and Martin (1891). Schneider and Macrides (1978) subsequently proposed that in the hamster EPL, Van Gehuchten (VG) cells interact with granule cell dendrites. More recently, multipolar neurons with morphological features of VG cells and SA cells have been identified in the rat EPL using staining methods for neuropeptides (Gall et al., 1986), NADPH diaphorase (Scott et al., 1987), and $\mathrm{Ca}^{2+}$-binding proteins (Briñón et al., 1992; Kosaka et al., 1994). Both the VG and SA cells typically have varicose dendrites that branch within either the superficial or deep half of the EPL. The VG cells have more elaborate dendritic arborizations near the cell body, however, and the SA cells have axons. With parvalbumin immunostaining methods, multipolar neurons with more widely branching dendrites that are either varicose or relatively smooth have also been observed throughout the EPL. Moreover, neurons with intermediate branching patterns between the VG, SA, and multipolar types have been observed, suggesting that EPL interneurons may comprise a single morphological continuum (Kosaka et al., 1994).

At the ultrastructural level, the parvalbumin-immunoreactive (IR) interneurons of the rat EPL appear to receive type 1 synapses from $\mathrm{M} / \mathrm{T}$ cells and to form type 2 synapses onto the $\mathrm{M} / \mathrm{T}$ cells, $\sim 30-50 \%$ of which are reciprocal (Toida et al., 1996). At least some of the parvalbumin-IR interneurons are also GABA-IR (Kosaka et al., 1987). In addition, $E P L$ interneurons are strongly IR for the glutamate receptor 1 (GluR1) $\alpha$-amino-3-hydroxy-5-methylisoxazole-4propionic acid (AMPA) receptor subunit (Petralia and Wenthold, 1992; Giustetto et al., 1997; Montague and Greer, 1999). Immunoreactivity for GluR1 (Hamilton and Coppola, 2003) and for parvalbumin (Philpot et al., 1997) is greatly reduced following neonatal naris occlusion, a procedure that deprives the olfactory system of airborne odor stimulation and alters olfactory bulb development.

Together, these observations suggest that the interneurons of the EPL are responsive to the afferent sensory input via $M / T$ cells and might in turn inhibit the $M / T$ cells. To investigate these possibilities, we have initiated electrophysiological studies of EPL interneurons in mouse olfactory bulb slices. Here, we show that interneurons resembling the VG and parvalbumin-IR multipolar interneurons of the rat have dendritic arbors that are spatially related to several adjacent glomeruli, are excited spontaneously via AMPA/kainate receptors, and receive polysynaptic inputs from the ON.

\section{EXPERIMENTAL PROCEDURES}

\section{Recording methods}

Juvenile and mature 22-34 day old C57BL/6J mice from Jackson Laboratories (Bar Harbor, ME, USA) and transgenic mice reared at the University of Maryland, Baltimore, MD, USA, were used.
The transgenic mice expressed enhanced green fluorescent protein (GFP) under control of the regulatory region of the $65 \mathrm{kDa}$ mouse glutamic acid decarboxylase (GAD) 65 gene (Erdélyi et al., 2002; Galarreta et al., 2004). Horizontal slices (400 $\mu \mathrm{m}$ thick) were obtained using a vibratome (Series 1000, Ted Pella Inc., Redding, CA, USA) as previously described (Heyward et al., 2001). The slices were sectioned in cold artificial cerebrospinal fluid (ACSF), immersed for $30-60 \mathrm{~min}$ in ACSF at $30^{\circ} \mathrm{C}$, and stored in ACSF at room temperature prior to recording. For recording, the slices were superfused with $30^{\circ} \mathrm{C} \mathrm{ACSF}$ at the rate of $1.5-3.0 \mathrm{ml} / \mathrm{min}$. The ACSF solutions contained (in $\mathrm{mM}$ ) $\mathrm{NaCl} 120$, $\mathrm{KCl} 3, \mathrm{MgCl}_{2} 1.3, \mathrm{CaCl}_{2} 1.3$, glucose $10, \mathrm{NaHCO}_{2} 25$, BES $5(300$ mOsm), and were $\mathrm{pH} 7.27$ with saturated $95 \% \mathrm{O}_{2}+5 \% \mathrm{CO}_{2}$. To study excitatory postsynaptic potentials and currents (EPSP/Cs), the normal ACSF was switched to ACSF containing the AMPA/ kainate receptor antagonist 6-cyano-7-nitroquinoxaline-2,3-dione (CNQX, $10 \mu \mathrm{M}$, Tocris Cookson, Ltd., Ellisville, MO, USA) or $1 \mu \mathrm{M}$ tetrodotoxin (TTX). Unless otherwise specified, chemicals were obtained from Sigma (St. Louis, MO, USA).

Pipettes were pulled from $1.5 \mathrm{~mm}$ O.D. borosilicate glass with internal filament using a Flaming-Brown $\mathrm{P}-97$ puller. They were filled with $\mathrm{K}^{+}$-gluconate $144, \mathrm{NaCl} 2, \mathrm{MgCl}_{2} 2$, EGTA 0.2, $\mathrm{Mg}_{2}$ ATP 2, $\mathrm{Na}_{3}$ GTP 0.2, HEPES 10, pH 7.04 (280 mOsM), which contained $0.1 \%$ biocytin (Molecular Probes or Sigma). Cells were visually identified in the EPL using a microscope equipped with near-infrared differential interference contrast and/or epifluorescence optics (Olympus Optical, Tokyo, Japan). Cell body recordings were then obtained using a Multiclamp $700 \mathrm{~A}$ or an Axopatch 200B amplifier, Digidata 1322A or 1200 data acquisition system, and pClamp software (Axon Instruments, Foster City, CA, USA). The recordings were low-pass Bessel filtered at $2 \mathrm{kHz}$ and digitized at $10 \mathrm{kHz}$ for subsequent analysis. The electrode resistance (5-15 $\mathrm{M} \Omega$ ) was compensated in the bath in current clamp mode before approaching cells. Series resistance was compensated $\sim 60-70 \%$. Recordings were discontinued if there was a sudden increase in the series resistance (e.g. $>30 \mathrm{M} \Omega$ ). Measurements were not corrected for the liquid junction potential $(9-10 \mathrm{mV})$.

\section{Resting and spontaneous activity}

Resting membrane voltage was generally measured immediately after establishing whole-cell configuration. For cells that exhibited spontaneous action potentials, the resting potential was measured immediately after an action potential or action potential burst. Spontaneous synaptic activity was analyzed in both current and voltage clamp modes. The high spontaneous EPSP frequency, EPSP summation, and voltage fluctuations of the interneurons (see Fig. 2A) precluded error-free use of automated template- and threshold-based counting routines in current clamp mode. Therefore, the maximum EPSP frequency of each interneuron was estimated by counting manually the EPSP peaks in five $0.1 \mathrm{~s}$ high-frequency intervals, taken from a 20-30 s recording. The same method was used to estimate the maximum action potential frequency of tufted cells. The effects of TTX on the spontaneous synaptic activity of the interneurons were analyzed in voltage clamp mode as follows. The Clampfit threshold event detection routine (Axon Instruments) was used to compare the last 50 EPSCs that occurred before and during TTX superfusion. With this method, EPSCs were visually inspected and those with amplitudes two times the baseline noise level were accepted. The inter-event intervals were then calculated and imported into SigmaStat 2.0 (SPSS, Inc., Chicago, IL, USA) to determine the mean EPSP frequency. SigmaStat was also used for statistical comparisons. The mean ( \pm S.E.M.) is reported throughout the text.

Autocorrelation analyses were used to determine if the spontaneous EPSCs of the interneurons occurred rhythmically, as previously reported (Hayar et al., 2004a). Briefly, 1-2 min segments of voltage-clamp recordings obtained from 16 of the interneurons were first analyzed using Mini Analysis Program (Synap- 
tosoft Inc., Decatur, GA, USA) to determine the EPSC peak amplitudes and times. Consecutive epochs of data (Parameter 1, e.g. $12 \mathrm{~ms}$ ) were searched for a peak current and the average baseline current was calculated for an interval defined by Parameters 2 and 3 (typically $3-4 \mathrm{~ms}$ ) before the peak. The EPSC amplitude was calculated by subtracting the average baseline current from the peak current, and the EPSC was rejected if the amplitude did not exceed a given threshold defined as Parameter $A$ (e.g. 6 pA). The parameters $P 1, P 2, P 3$, and A were varied so that at least $95 \%$ of the visually identified EPSCs were automatically detected. The EPSC amplitudes and times were then imported into Origin 7.0 (OriginLab Corporation, Northamptom, MA, USA). Autocorrelograms were generated using 1 or $2 \mathrm{~ms}$ bins and normalized to the square value of the EPSC frequency, the bin width, and the sampling period by dividing the counts in each bin by a coefficient $(N)$, which is the number of events expected by chance during one bin: $N=F \times F \times P \times B$, where $F$ is the mean frequency $(\mathrm{Hz})$ of EPSCs during the sampling period, $P$ is the sampling period (s), and $B$ is the bin duration (s) (Mann-Metzer and Yarom, 1999; Hayar et al., 2004a). With this method, the correlation coefficient $(C)$ indicates how frequently a cell exhibits EPSCs in one bin relative to chance $(C=1)$. A correlation coefficient greater than $1+3 \times$ S.D., where S.D. is the standard deviation of the autocorrelation of the spike train at time lags between 1.5 and $2.0 \mathrm{~s}$, indicates significant positive correlation (i.e. confidence limit $>99.97 \%$; shift predictor method, Gerstein and Perkel, 1972).

\section{Evoked responses}

The ON layer was stimulated using 100-200 $\mu$ s constant current pulses delivered at a range of intensities with a bipolar electrode fabricated from 25 to $50 \mu \mathrm{m}$ nichrome or stainless steel wires insulated except at the tips. The postsynaptic response latency was determined as the latency from the stimulus artifact to the onset of the evoked depolarization or inward current. To assess the synaptic jitter of the interneuron responses, the standard deviations of the latencies of the evoked responses were averaged (Doyle and Andresen, 2001). To estimate the response durations, the current-clamp recordings were summed for each cell and the time required for the trace to return to the base line was measured. Analysis of variance tests revealed no significant effects of repeated stimulation of the same cell (Friedman ANOVA; $P>0.05$ ). Data were therefore averaged to generate group means for the interneurons, tufted cells, and astrocytes.

Membrane properties and cellular excitability were examined by delivering 300-400 ms constant current pulses and slow depolarizing ramps. The input resistance and time constant were measured in responses to small hyperpolarizing steps. Firing latency was measured in responses to near-threshold depolarizing steps. The voltage change during these responses was measured by subtracting the voltage at the end of the pulse from the voltage at a time point equal to the time constant. Firing frequency was measured in responses to suprathreshold depolarizing steps that generated at least 11 action potentials (interneurons) or during spontaneous action potential bursts (tufted cells). Characteristics of evoked action potentials were measured in responses to slow depolarization near the threshold

\section{Histological methods}

After recording, slices were fixed in $4 \%$ paraformaldehyde in $0.1 \mathrm{M}$ $\mathrm{Na}^{+}$phosphate buffer or in $2.5 \%$ paraformaldehyde in phosphate buffer containing $15 \%$ saturated picric acid $+1.5 \%$ glutaraldehyde. The slices were embedded in $10 \%$ gelatin, sectioned at 60-100 $\mu \mathrm{m}$ thickness using a vibratome, and processed using immunoperoxidase methods ( $A B C$ Elite and $D A B$ kits, Vector Laboratories, Burlingame, CA, USA) to permanently stain the recorded cells. Measurements were obtained using a microscope equipped with a calibrated ocular micrometer, and photomicro- graphs were obtained using a microscope equipped with a PowerPhase camera (Phase One Inc., Northport, NY, USA). Images of GAD65-GFP cells in the live slices were obtained using a CCD 100 camera (Dage-MTI, Michigan City, IN, USA) and video card (Scion Corporation, Frederick, MD, USA). The brightness, contrast, color balance, and sharpness of the images were optimized using Adobe Photoshop 6.0 (San Jose, CA, USA).

\section{RESULTS}

\section{Morphology}

Voltage- and current-clamp recordings were obtained from 20 histologically verified interneurons: 12 in slices from C57BL/6J mice and eight in slices from GAD65-GFP mice. All 20 of the interneurons were distinguished by their varicose processes (Fig. 1A, B, and D). The cell bodies were round-to-oval in shape, with average major and minor dimensions of $12.6 \pm 0.6 \mu \mathrm{m}$ (mean \pm S.E.M.) and $9.1 \pm 0.4$ $\mu \mathrm{m}$, respectively. Both the $\mathrm{GL}$ and mitral cell layer (MCL) borders were visible in sections containing 19 of the cell bodies, 15 of which were located in the superficial half of the EPL $(54 \pm 11 \mu \mathrm{m}$ from the GL, $143 \pm 12 \mu \mathrm{m}$ from the MCL) and four of which were located in the deep half of the EPL $(157 \pm 10 \mu \mathrm{m}$ from the $\mathrm{GL}, 71 \pm 25 \mu \mathrm{m}$ from the MCL). No significant differences in soma size or dendritic extent (see below) were observed between the superficial and deep interneurons, or between the two mouse strains.

The interneurons resembled the VG and parvalbumin-IR multipolar interneurons described in the hamster and rat (Schneider and Macrides, 1978; Kosaka et al., 1994). As with the hamster and rat interneurons, two poles of the cell body typically gave rise to two-to-four processes, which were gradually tapering, suggesting that they were dendrites. The dendrites branched immediately (Figs. 1A and $3 \mathrm{~A}$ ) or at various distances from the cell body (Fig. 1B and D), giving rise to an oval or conical dendritic tree. For seven of the 15 superficial interneurons and three of the four deep interneurons, the maximum linear extent of the dendritic tree occurred within a single section, and it measured $126 \pm 8 \mu \mathrm{m}$. This is similar to the mean diameter of the 10 largest of 32 glomeruli measured in one section, $115 \pm 4 \mu \mathrm{m}$. As shown in Fig. $1 A$ and $B$, the dendrites of the superficial interneurons bridged the EPL space below several adjacent glomeruli. As shown in Fig. 1D, the dendrites of deeper interneurons appeared to bridge an EPL area of similar size.

One-to-three spines were visible on the dendrites of six of the 20 interneurons, two of which were located in the superficial half of the EPL and four of which were located in the deep half of the EPL (Fig. 1D). Spines on the other interneurons might not have been visible due to their small sizes and to the depth of the processes in the tissue sections. None of the 20 mouse interneurons exhibited identifiable axons, similar to the findings for $V G$ and parvalbumin-IR interneurons described previously (see Kosaka et al., 1994).

Small numbers of two other cell types with similarly sized cell bodies were also recorded in the EPL of the C57BL/6J mouse slices and are included here for comparison with the EPL interneurons. Four superficial and inter- 
mediate tufted cells (Fig. 1F and G, respectively) and one internal tufted cell (not shown) were recorded. Properties of EPL tufted cells have previously been studied by others (Schneider and Scott, 1983; Ezeh et al., 1993; Christie et al., 2001; Belluzzi et al., 2004). The tufted cells were identified by their glomerular tufts, lateral dendrites, and depth within the EPL (Orona et al., 1984; Ezeh et al., 1993). The major axis of the tufted cell bodies ranged from 12 to $18 \mu \mathrm{m}$ (mean $13.8 \pm 1.7 \mu \mathrm{m}, n=4$ ). In addition, three astrocytes (Fig. 1H) were recorded in the slices. The astrocytes were identified by their octopus-like morphology (Bailey and Shipley, 1993). The major axis of the astrocyte cell bodies ranged from 9.6-11.2 $\mu \mathrm{m}(n=2)$. Unusually large astrocytes have previously been reported to occur throughout the olfactory bulb layers of C57BL/6J mice (Mirich et al., 2002).

\section{Electrophysiological characteristics}

The resting membrane potential of the interneurons $(-77.8 \pm 0.9 \mathrm{mV}, n=20)$ was similar to that of the astrocytes $(-77.1 \pm 3.6 \mathrm{mV}, n=3)$, but it was significantly more hyperpolarized than that of the tufted cells $(-59.4 \pm 5.1$ $\mathrm{mV}, n=5, P<0.001$; ANOVA with Student-Newman-Keuls comparisons). The mean input resistance of the interneurons $(420 \pm 67 \mathrm{M} \Omega, n=19)$ was similar to that of the tufted cells $(330 \pm 53 \mathrm{M} \Omega, n=4)$, but it was significantly greater than that of the astrocytes $(47 \pm 9 \mathrm{M} \Omega, n=3, P<0.05$; Kruskal-Wallis ANOVA with Dunn's comparisons). By contrast, the membrane time constant of the interneurons $(11.2 \pm 1.3 \mathrm{~ms}, n=19)$ was significantly shorter that of the tufted cells $(26.8 \pm 7.9 \mathrm{~ms}, n=4, P=0.001)$, and it was significantly longer than that of the astrocytes $(0.8 \pm 0.2 \mathrm{~ms}$, $n=3, P=0.036$; ANOVA with Student-Newman-Keuls comparisons). These results show that membrane properties can be used to distinguish similarly sized interneurons, tufted cells, and astrocytes in the mouse EPL. The membrane properties of the interneurons are considered further below.

\section{Spontaneous activity}

The interneurons were also readily identifiable by their spontaneous synaptic activity. At the resting membrane potential, high-frequency spontaneous EPSP/Cs were manifest in all 20 of the interneurons. As shown in Fig. 2A, the spontaneous EPSPs exhibited sporadic increases in frequency that were often associated with slow membrane

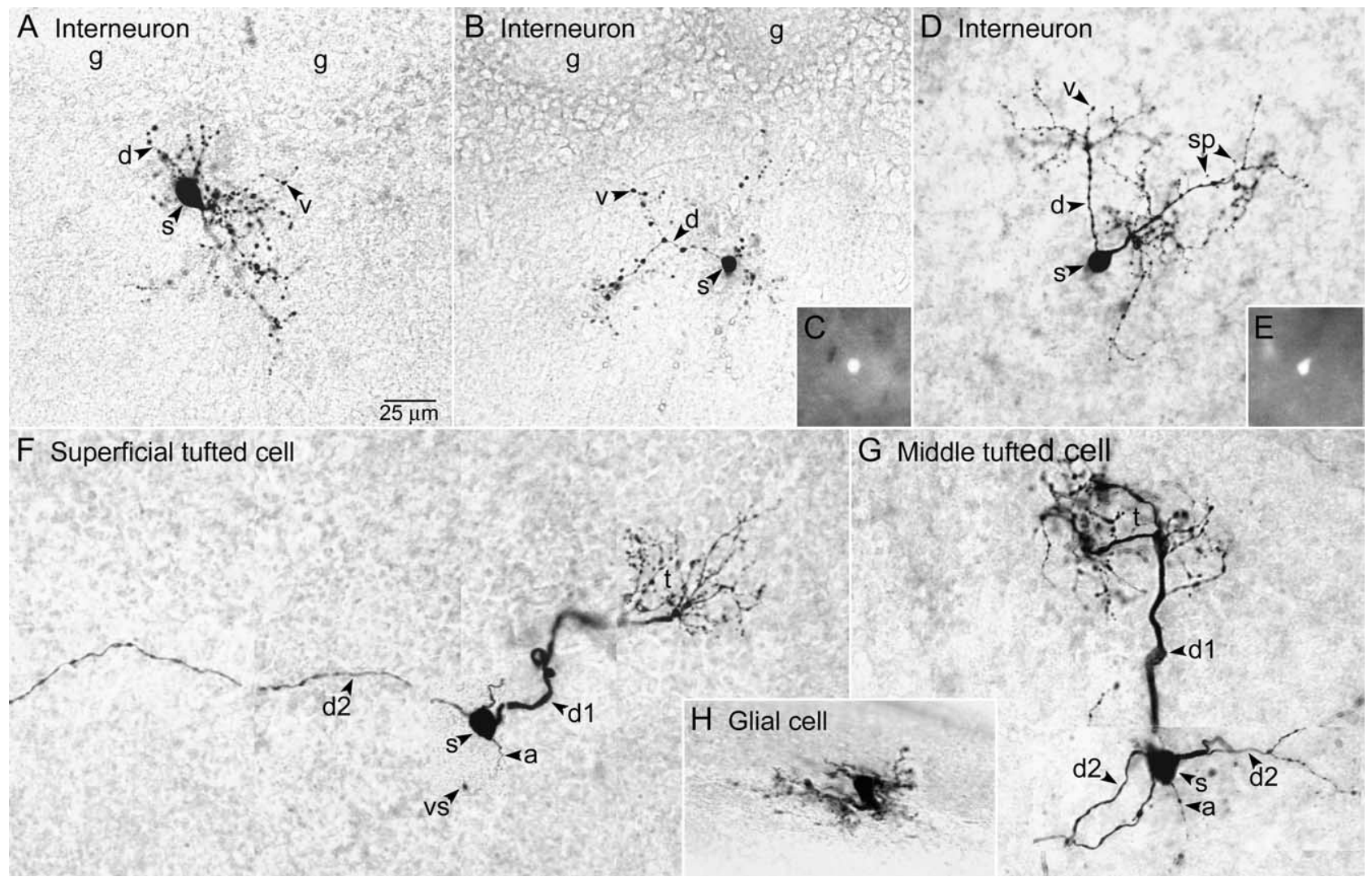

Fig. 1. Morphological characteristics of cells in the $E P L$ of $C 57 B L / 6 J$ mice ( $A$ and $F-H)$ and GAD65-GFP mice (B-E). Single sections (A-E and $H$ ) or montages ( $F$ and $G$ ) illustrate the cell body (s, soma), major portion of the dendritic tree, and axon (a, if present). (A, B) The dendrites (d) of superficial interneurons located near the GL bridged the EPL space below several adjacent glomeruli $(\mathrm{g})$. The $\mathrm{d}$ had numerous varicosities ( $\mathrm{v}$ ), and some had sparse spines (sp, Fig. 1D). (C) Epifluorescence image of GFP in the soma of the cell shown in Fig. 1B, in the unfixed slice. (D) An interneuron exhibiting similar characteristics located deeper in the EPL. Two major d extended toward the GL. (E) Epifluorescence image of GFP in the soma of the cell shown in Fig. 1D. (F) Superficial tufted cell with short primary d (d1) giving rise to a glomerular tuft (t) and long secondary $d(d 2)$ extending laterally in the EPL. (G) Middle tufted cell with d1 giving rise to a $t$ and multiple d2 extending laterally in the EPL. (H) Astrocyte. 

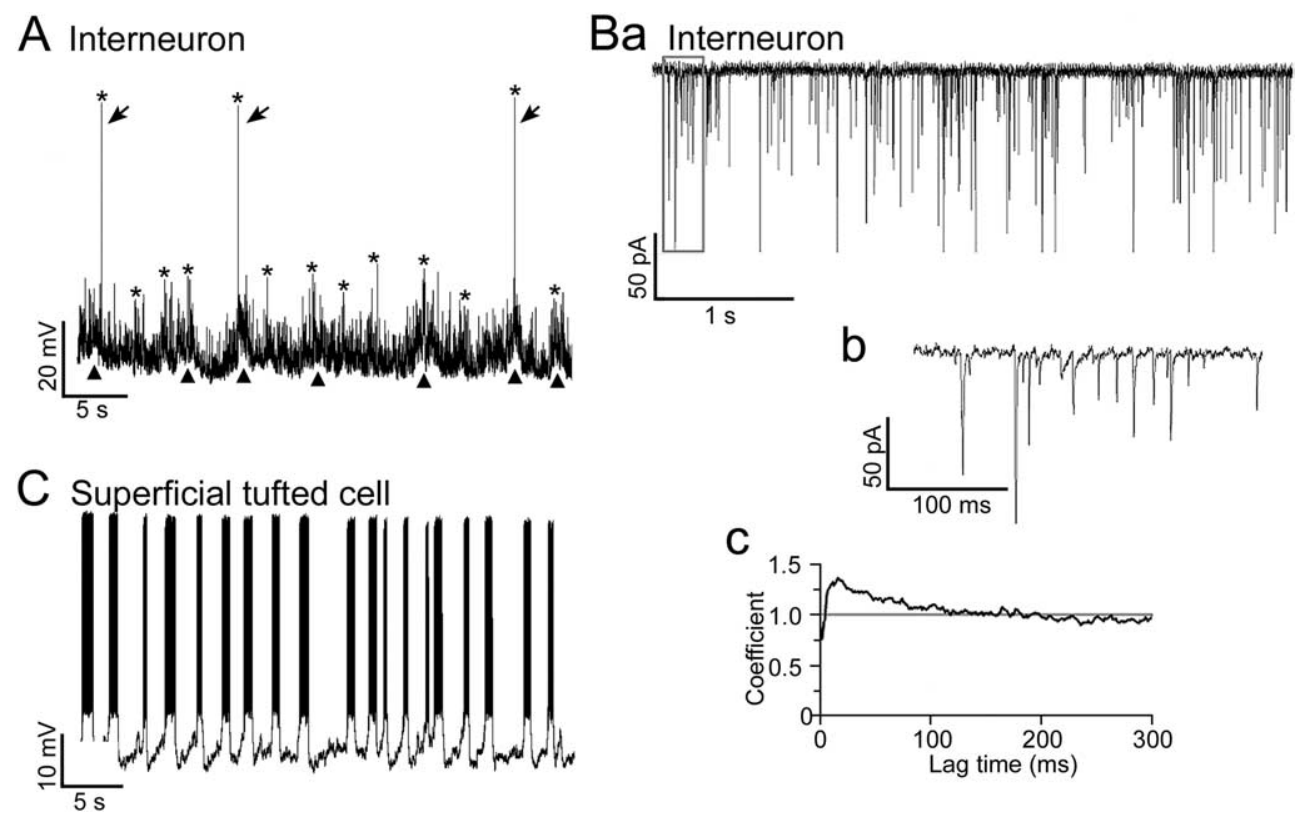

Fig. 2. Spontaneous synaptic activity of EPL interneurons and spiking activity of tufted cells. (A) Current clamp recording from the interneuron shown in Fig. 1A. Note the high-frequency of spontaneous EPSPs and occasional action potentials (arrows). Asterisks indicate peaks of sporadic increases in the EPSP/action potential frequency (maximum for this cell, 188 $\pm 18, n=5$ ). Note the fluctuations in membrane potential (triangles) often associated with the increases in EPSP frequency. The resting membrane potential was $-75 \mathrm{mV}$. (Ba) Voltage clamp recording from another interneuron near the resting membrane potential $(-80 \mathrm{mV})$. The mean EPSP frequency of the interneuron was $42 \mathrm{~Hz}$, which was relatively low. (Bb) Expanded view of the boxed area in Fig. 2Ba. (Bc) Autocorrelation coefficient for the EPSC trains of the same interneuron. Interneurons with relatively low EPSC frequencies exhibited significant autocorrelation near zero time lag (confidence limit $>99.97 \% ; C=1$ indicates chance occurrence), indicating that the EPSCs had a tendency to occur in bursts. (C) Current clamp recording from the superficial tufted cell shown in Fig. $1 \mathrm{~F}$. Action potentials with a mean frequency of $42 \pm 6 \mathrm{~Hz}$ occurred in bursts at a rate of $0.52 \pm 0.06 \mathrm{~Hz}(n=5)$. The resting membrane potential, measured during inter-burst intervals, was $-56 \mathrm{mV}$.

potential depolarizations. As shown in Fig. 2Ba and b, sporadic increases in EPSC frequency were also observed in interneurons that were voltage-clamped at holding potentials equal to the resting membrane potential. These EPSP/C frequency increases occurred at a rate of $0.56 \pm 0.03$ $\mathrm{Hz}(n=20)$. The mean EPSC frequency of the voltageclamped interneurons was $74 \pm 10 \mathrm{~Hz}$ (range $21-146 \mathrm{~Hz}$, $n=16$ ).

To determine if the EPSC trains exhibited rhythmic activity, we performed autocorrelation analyses (Berretta et al., 2001; see Experimental Procedures). As shown in Fig. $2 \mathrm{Bc}$, six of 16 voltage-clamped interneurons exhibited significant autocorrelation coefficients $(C=1.18 \pm 0.04$, range 1.10-1.38, confidence limit $>99.97 \%$ ) near zero lag time. For these interneurons, the mean inter-EPSC interval with the highest probability (i.e. lag time of peak $C$ values) was $26 \pm 9 \mathrm{~ms}$ (range $6-65 \mathrm{~ms}$ ). The mean EPSC frequency of the six interneurons was $36 \pm 4 \mathrm{~Hz}$ (range 21$48 \mathrm{~Hz}$ ), which was significantly lower than that of the other 10 interneurons (mean $97 \pm 11 \mathrm{~Hz}$, range $33-146 \mathrm{~Hz}$; $P<0.001$, unpaired $t$-test). These results indicate that EPL interneurons with relatively low EPSC frequencies are more likely to exhibit distinct bursts of EPSCs, which is an indication that the cells receive correlated excitatory synaptic inputs from presynaptic neurons.

We next used pharmacological agents to analyze the receptors involved in mediating the EPSP/Cs of the interneurons, and to determine if the EPSP/Cs were action potential-dependent. As illustrated in Fig. $3 \mathrm{Ba}$ and $\mathrm{b}$, the
EPSC amplitude ranged from $-6 \mathrm{pA}$ to over $-500 \mathrm{pA}$. As shown in Fig. 3Ba and $\mathrm{C}$, in all 10 interneurons tested, EPSP/Cs were largely if not completely eliminated by the AMPA/kainate receptor antagonist CNQX $(10 \mu \mathrm{M})$. Three slices were also superfused with the sodium channel blocker TTX $(1 \mu \mathrm{M})$, to block action potential propagation in the slice. As shown in Fig. 3D and E, in all three trials, the EPSP/C frequency was significantly reduced, by $40-95 \%$ $(P<0.001$, Mann-Whitney rank sum tests). The EPSP/C amplitude also appeared to be reduced, but this was not quantified. These results indicate that the EPSP/Cs of the interneurons are largely evoked by the action potential activity of presynaptic neurons.

As shown in Fig. $2 \mathrm{C}$, four of the five tufted cells that were recorded in the EPL were spontaneously active. The spontaneous activity consisted of bursts of action potentials riding upon rhythmic membrane depolarizations. The action potential frequency of the four tufted cells, measured at the beginning of spontaneous action potential bursts, was $31.0 \pm 4.5 \mathrm{~Hz}$, which was similar to the $\sim 36 \mathrm{~Hz}$ mean EPSC frequency of the interneurons that exhibited significant autocorrelation. The mean burst frequency was $0.49( \pm 0.04 \mathrm{~Hz}, n=4)$, which was also similar to the mean $0.56 \mathrm{~Hz}$ rate of the sporadic EPSP/C frequency increases observed in the interneurons. The spontaneous synaptic activity of the tufted cells was difficult to assess because of this spiking. However, when the tufted cells were hyperpolarized (Fig. 4C), very few spontaneous EPSPs were observed. Thus, both the spontaneous synaptic and spik- 


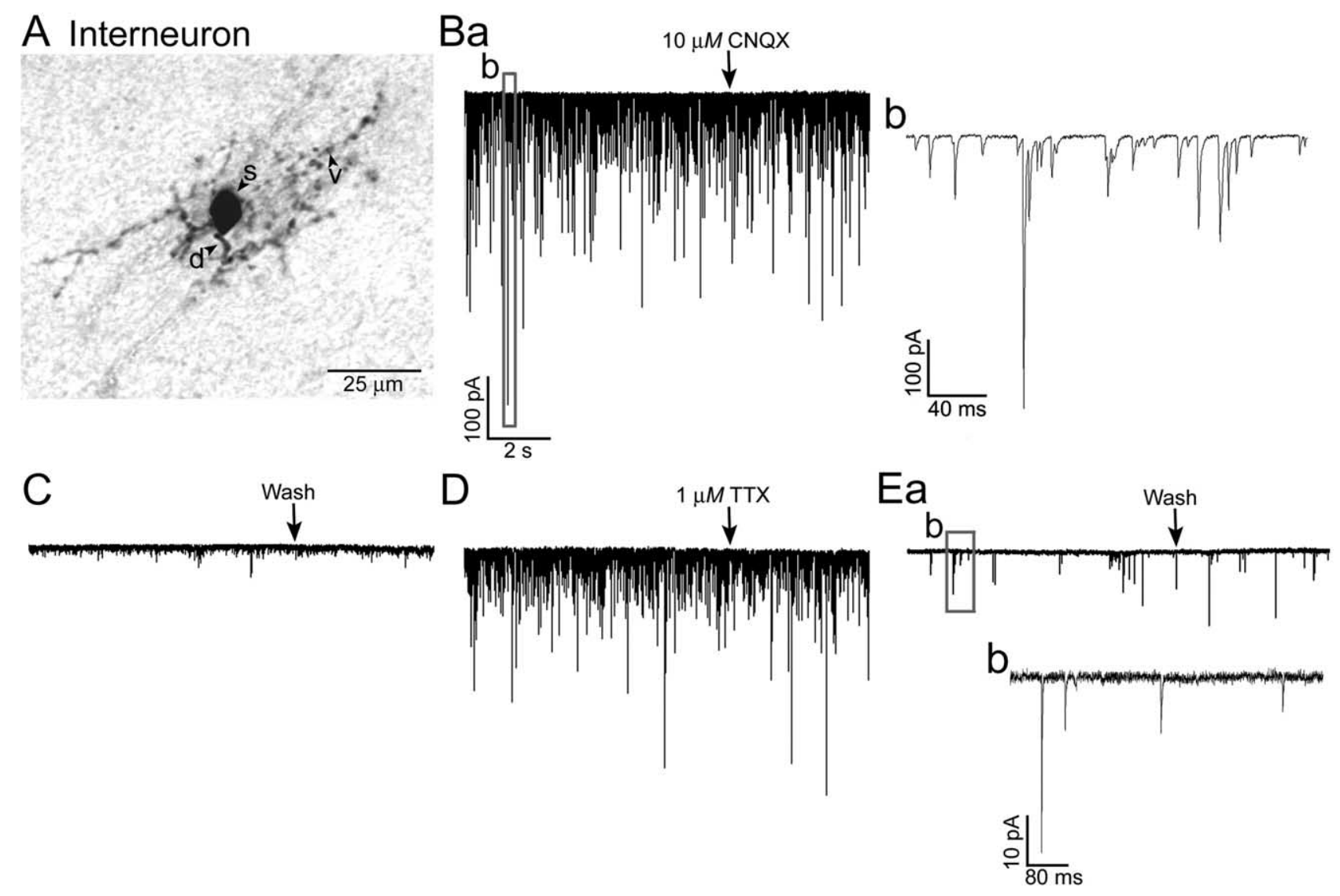

Fig. 3. Effects of CNQX and TTX on EPSCs in EPL interneurons. (A) Photomicrograph of an EPL interneuron from a C57BL/6J mouse. (Ba) Voltage-clamp recording from the same cell showing spontaneous EPSCs before CNQX superfusion and at the beginning of the CNQX superfusion $(10 \mu \mathrm{M}$, at the arrow). Note the wide range of EPSC amplitudes. The boxed area is expanded in Fig. 3Bb. (C) After 8.7 min in CNQX, few EPSCs remained, and the slice was superfused with normal ACSF (Wash, at the arrow). (D) After 45 min in normal ACSF, spontaneous EPSC activity had largely recovered, and the slice was then superfused with TTX $(1 \mu \mathrm{M}$, at the arrow). (Ea) The EPSC frequency was greatly reduced after 33.4 min in TTX, and relatively few EPSCs were observed; those in the boxed area are enlarged in Fig. 3Eb. Scales for Fig. 3C, D, and Ea as in Fig. 3Ba.

ing activity of EPL interneurons and tufted cells differ markedly.

\section{Evoked responses}

In eight of the 13 interneurons tested, ON stimulation evoked a depolarization that appeared to result from the summation of multiple, high-frequency EPSP/Cs (Fig. 4Aa). For the five interneurons recorded in current clamp mode, the ONevoked depolarization had a mean latency of $5.1 \pm 0.3 \mathrm{~ms}$ and a mean duration of $0.97 \pm 0.22 \mathrm{~s}$. The mean of the standard deviations of the response latencies, a measure of synaptic variability or "jitter" (Doyle and Andresen, 2001), was $1.28 \mathrm{~ms}( \pm 0.37 \mathrm{~ms}, n=5)$. For the six interneurons recorded in voltage clamp mode (e.g. Fig. 4Ab), the mean standard deviation of the response latencies was somewhat smaller, $0.53 \pm 0.18 \mathrm{~ms}$. The long latency and large synaptic jitter indicate that the interneuron responses are polysynaptically linked to the ON (Hayar et al., 2004b).

Only four of the eight interneurons that responded to ON stimulation produced action potentials/currents. However, depolarizing current injection evoked action potentials in all 18 of the interneurons that were tested. In 14 of the 18 interneurons, action potentials were evoked after a significant delay (222.0 $26.7 \mathrm{~ms}$; Fig. 4Ac), and they were superimposed on a small depolarizing ramp $(9.0 \pm 0.8 \mathrm{mV}$; Fig. 4Ad). As shown in Fig. 4Ad, in response to nearthreshold stimulation, the action potentials tended to occur irregularly. These response properties are similar to those of late-spiking interneurons found in neocortex (Kawaguchi, 1995; Chu et al., 2003) and perirhinal cortex (McGann et al., 2001). Half (six of 11) of the interneurons that exhibited delayed firing in response to near-threshold stimulation exhibited minimal delay in response to suprathreshold stimulation. Nine of the interneurons that exhibited delayed-firing in response to near-threshold stimulation (including the cells in Figs. 1B and 4Ac) and one interneuron that exhibited minimal delay responded to suprathreshold stimulation with prolonged trains of at least 10 action potentials. Properties of these 10 interneurons are summarized in Table 1. The coefficient of variation for the 10 inter-spike intervals of the spike trains was $0.09 \pm 0.05$, indicating that action potentials occurred regularly. This response property is similar to that of fast-spiking interneurons found in neocortex (Kawaguchi, 1993, 1995; Galarreta and Hestrin, 2002) and perirhinal cortex (McGann et al., 2001). The membrane time constant of the 10 inter- 


\section{A Interneurons}

\section{a}

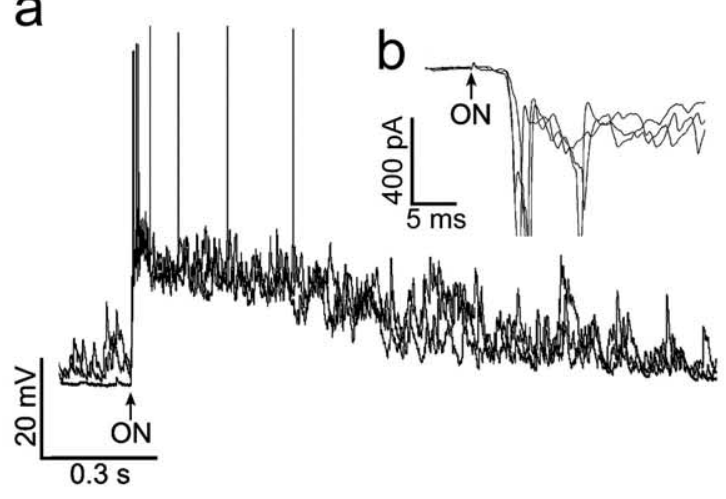

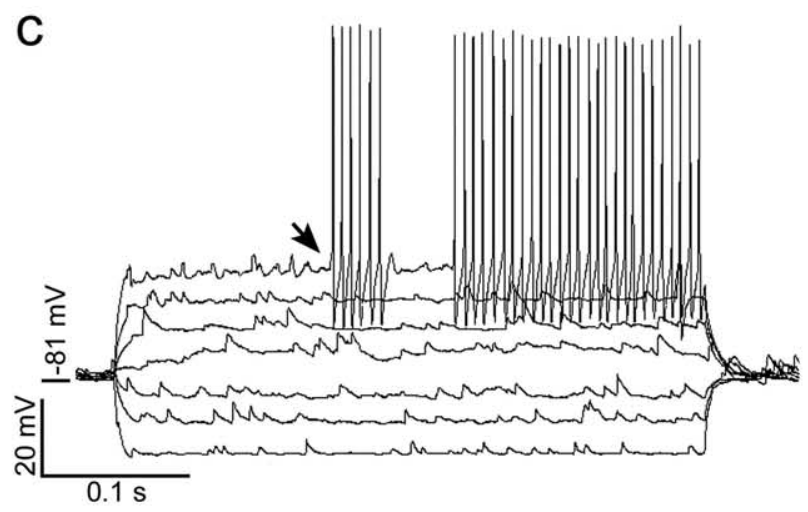

\section{B Superficial tufted cell}

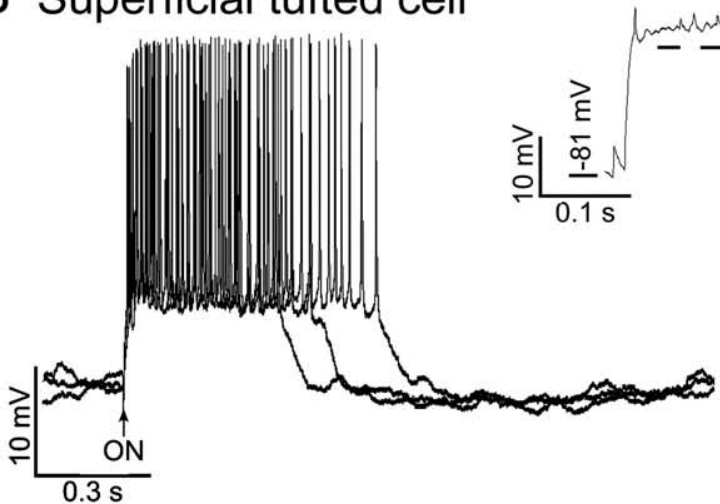

\section{Glial cell}
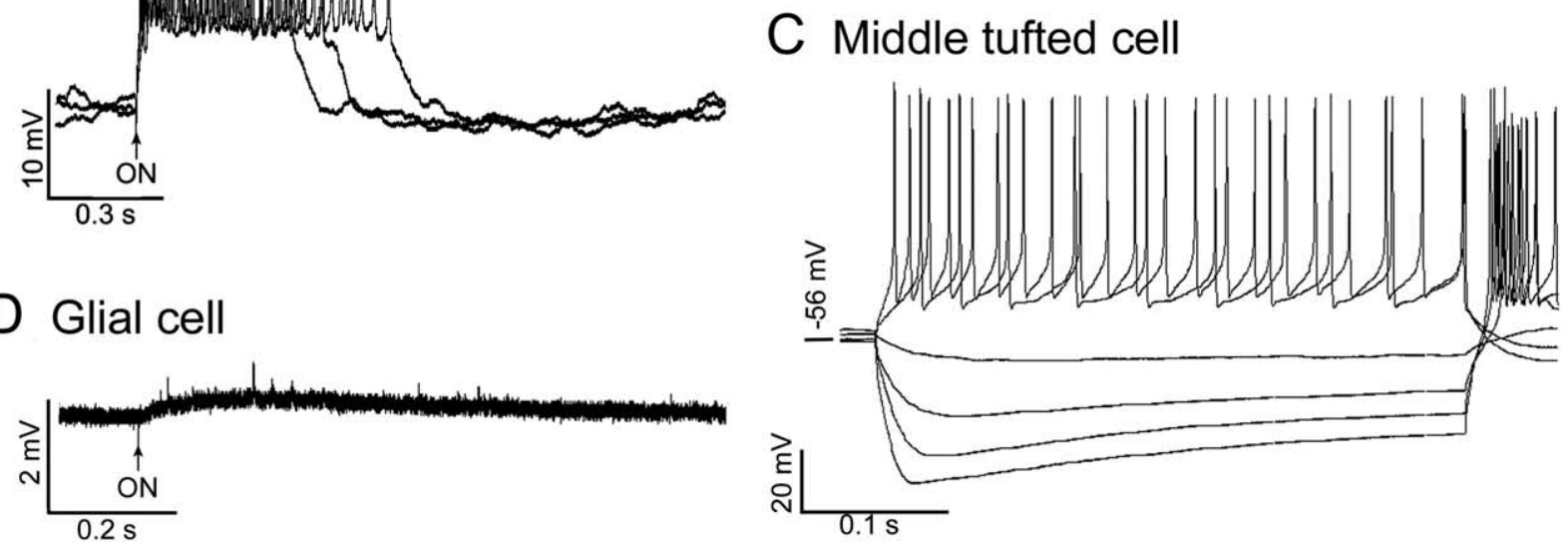

Fig. 4. Evoked responses of EPL interneurons (A) and tufted cells (B and C). A recording from a glial cell (D) is also shown for comparison. (Aa) Response of the interneuron shown in Fig. $1 A$ to ON stimulation, which evoked a depolarization and burst of action potentials. Three overlapping traces are shown. The resting membrane potential was $-75 \mathrm{mV}$. (Ab) Voltage-clamp recordings of responses of the interneuron to ON stimulation (three overlapping traces). The mean latency was $3.4 \pm 0.15 \mathrm{~ms}(n=4)$. (Ac) Responses of another interneuron to current pulses (400 ms duration, seven overlapping traces). Depolarizing current pulses evoked action potentials after a pronounced delay (arrow). The top response was to a suprathreshold pulse that evoked a prolonged train of action potentials. The resting membrane potential was $-81 \mathrm{mV}$. (Ad) Response of the same interneuron as in Fig. 4Ac to a near-threshold current pulse $(400 \mathrm{~ms})$. Note the depolarizing ramp (dashed line) and delayed firing (arrow). Action potentials have been cropped. (Ae) Response of the interneuron shown in Fig. 1D to a suprathreshold current pulse $(400 \mathrm{~ms})$. Note the brief burst of spikes, which rapidly became truncated. (B) Responses of the superficial tufted cell shown in Fig. $1 \mathrm{~F}$ to ON stimulation, which triggered a depolarization and action potential burst (three overlapping traces). The resting membrane potential was $-56 \mathrm{mV}$. (C) Responses of the middle tufted cell shown in Fig. $1 \mathrm{G}$ to current pulses (400 ms duration, six overlapping traces). Depolarizing pulses evoked action potentials, after a minimal delay with the lower currents. The resting membrane potential was $-56 \mathrm{mV}$. $(\mathrm{H})$ Response of the astrocyte shown in Fig. $1 \mathrm{H}$ to ON stimulation, which consisted of a slow depolarization and fast transients of unknown origin that also occurred spontaneously. The resting membrane potential was $-82 \mathrm{mV}$.

neurons (9.8 $\pm 1.2 \mathrm{~ms})$ and their action potential characteristics were also similar to those of the fast-spiking cortical and perirhinal interneurons; the action potentials were brief $(0.25 \pm 0.02 \mathrm{~ms})$, over-shooting $(13.6 \pm 2.5 \mathrm{mV})$, and under our recording conditions appeared to be followed by a single-component after-hyperpolarization (1.2 $\pm 0.1 \mathrm{~ms}$ timeto-peak) with an amplitude of $-17.3 \pm 1.3 \mathrm{mV}$ (Table 1). The input resistance $(306 \pm 22 \mathrm{M} \Omega$, Table 1) was somewhat higher, however, closer to that of the late-spiking cortical and perirhinal interneurons (250-550 M , Kawaguchi, 1995; McGann et al., 2001; Chu et al., 2003).

As shown in Fig. 4Ae, four of the $18 \mathrm{EPL}$ interneurons tested with depolarizing current steps (including the cell shown in Fig. 1D) produced brief trains of action potentials at the beginning of the pulse. The spikes rapidly became truncated, but in two of the four cells, action potentials 
Table 1. Properties of EPL interneurons that produced prolonged spike trains in response to suprathreshold depolarization ${ }^{\text {a }}$

\begin{tabular}{|c|c|}
\hline Soma major axis $(\mu \mathrm{m})$ & $12.0 \pm 0.8$ \\
\hline Soma minor axis $(\mu \mathrm{m})$ & $8.8 \pm 0.5$ \\
\hline Dendritic extent $(\mu \mathrm{m})^{\mathrm{b}}$ & $146 \pm 14$ \\
\hline Resting potential (mV) & $-78.5 \pm 1.4$ \\
\hline Spontaneous EPSP/C frequency ${ }^{\mathrm{C}}$ & $134 \pm 13$ \\
\hline Input resistance $(\mathrm{M} \Omega)^{\mathrm{d}}$ & $306 \pm 22$ \\
\hline Time constant $(\mathrm{ms})^{\mathrm{d}}$ & $9.8 \pm 1.2$ \\
\hline Spike threshold $(\mathrm{mV})^{\mathrm{e}}$ & $-47.3 \pm 0.1$ \\
\hline Spike height $(\mathrm{mV})^{\mathrm{e}, \mathrm{f}}$ & $60.7 \pm 2.5$ \\
\hline Spike overshoot $(\mathrm{mV})^{\mathrm{e}, \mathrm{f}}$ & $13.6 \pm 2.7$ \\
\hline Spike width at half amplitude $(\mathrm{ms})^{\mathrm{e}, \mathrm{f}}$ & $0.25 \pm 0.02$ \\
\hline After-hyperpolarization amplitude $(\mathrm{mV})^{\mathrm{e}, \mathrm{g}}$ & $-17.3 \pm 1.3$ \\
\hline After-hyperpolarization time-to-peak (ms) ${ }^{\mathrm{e}, \mathrm{h}}$ & $1.2 \pm 0.1$ \\
\hline Latency of first evoked spike $(\mathrm{ms})^{i}$ & $184.9 \pm 39.6$ \\
\hline Evoked firing frequency $(\mathrm{Hz})^{\mathrm{j}}$ & $156 \pm 11$ \\
\hline Coefficient of variation ${ }^{\mathrm{j}, \mathrm{k}}$ & $0.09 \pm 0.05$ \\
\hline
\end{tabular}

${ }^{a}$ Mean \pm S.E.M. for 10 interneurons (except dendritic extent $n=4$ ) that produced trains of $\geq 11$ action potentials in response to depolarizing current steps.

${ }^{\mathrm{b}}$ Largest linear extent of the dendritic tree visible in single sections.

${ }^{c}$ Measured during sporadic frequency increases.

${ }^{\mathrm{d}}$ Measured in responses to hyperpolarizing current pulses.

e Measured during slow depolarization from the resting membrane potential.

${ }^{f}$ Relative to the threshold voltage.

g Minimum voltage.

${ }^{\mathrm{h}}$ From the action potential peak to the minimum voltage.

i Measured in responses to near-threshold current pulses.

'Measured in responses to suprathreshold current pulses evoking $\geq 11$ action potentials.

${ }^{\mathrm{k}}$ S.D. $\div$ mean of 10 inter-spike intervals $(\times 1.025$ to correct for small sample size; Sokal and Rohlf, 1981).

were again observed at the very end of the pulse. The four briefly firing interneurons included two interneurons that exhibited delayed firing in response to near-threshold stimulation and two interneurons that exhibited minimal delay. These four interneurons exhibited significantly higher input resistances $(889 \pm 174 \mathrm{M} \Omega$ vs $306 \pm 22 \mathrm{M} \Omega, P=0.006$; Mann-Whitney rank sum test), longer time constants (17.7 $\pm 3.4 \mathrm{~ms}$ vs $9.8 \pm 1.2 \mathrm{~ms}, P=0.018$; $t$-test), and lower EPSC frequencies during the sporadic frequency increases $(76 \pm 9 \mathrm{~Hz}$ vs $134 \pm 13 \mathrm{~Hz}, P=0.020$; $t$-test) than the 10 prolonged-firing interneurons. The briefly firing interneurons might have been damaged, or they could represent a different cell type. Three of them exhibited EPSC bursts, and all four were located within the superficial half of the EPL. By contrast, only three of the 10 prolongedfiring interneurons exhibited EPSC bursts, and they were located in both the superficial (seven cells) and deep (two cells) EPL; the location of one prolonged-firing interneuron was not determined. The soma sizes (major axis 7.2$12.8 \mu \mathrm{m}$, minor axis 5.6-9.6 $\mu \mathrm{m}$ ) and dendritic extent $(84-126 \mu \mathrm{m})$ of the briefly firing interneurons fell within the ranges for the prolonged-firing interneurons $(7.2-14.4 \mu \mathrm{m}$, 6.4-11.2 $\mu \mathrm{m}$, and 110-176 $\mu \mathrm{m}$, respectively), but too few of the briefly firing interneurons were stained to permit statistical comparisons.

Three of the four tufted cells that were tested responded to ON stimulation with a large depolarization, either with (Fig. 4B, two cells) or without (one cell) an action potential burst. The latency of the tufted cell responses $(3.3 \pm 0.4 \mathrm{~ms}, n=3)$ was significantly shorter than that of the interneurons $(P=0.011 ; t$-test $)$, but the response duration $(1.12 \pm 0.44 \mathrm{~s}, n=3)$ did not differ significantly $(P=0.743$; $t$-test). The shorter latency of the tufted cell responses is consistent with ultrastructural studies showing that tufted cells receive type 1 synapses from ON axons within the glomeruli (Pinching and Powell, 1971). Little delay or spike truncation were observed in the tufted cell responses to depolarizing current injection (Fig. 4C).

The three astrocytes were not excited by ON stimulation or by depolarizing current injection. However, as shown in Fig. 4D, a slow depolarization was observed in two of the astrocytes in response to ON stimulation. Spontaneous voltage transients of unknown origin were also observed in two of the cells (Fig. 4D).

\section{DISCUSSION}

This study provides new information about the poorly understood interneurons found in the EPL of the main olfactory bulb. Biocytin staining shows that the mouse interneurons resemble the VG and parvalbumin-IR multipolar interneurons described in the hamster and rat using other staining methods (Schneider and Macrides, 1978; Kosaka et al., 1994). Like many of the hamster and rat interneurons, the mouse interneurons do not appear to bear axons. The axons of EPL interneurons might only be identifiable ultrastructurally, however (see Toida et al., 1996). Many of the mouse interneurons exhibit electrophysiological properties in common with late- and fastspiking interneurons found in other cortical regions, the latter of which have been shown to contain parvalbumin (Kawaguchi and Kubota, 1993, 1997; Galarreta and Hestrin, 2002). Additional studies are needed to determine if the mouse EPL interneurons are truly axonless, and also to determine if they are IR for parvalbumin or for other calcium binding proteins that distinguish subsets of cortical interneurons.

The most striking electrophysiological property exhibited by the mouse EPL interneurons is the occurrence of spontaneous $\mathrm{EPSP} / \mathrm{Cs}$ with relatively wide-ranging, fast frequencies $(\sim 30 \mathrm{~Hz}$ to $100 \mathrm{~Hz})$ and wide-ranging, large amplitudes $(\sim-6 \mathrm{pA}$ to $-500 \mathrm{pA})$. Large spontaneous EPSP/Cs (up to $-120 \mathrm{pA}$ ) have previously been observed in rat PG cells and SA cells (Wellis and Scott, 1990; Puopolo and Belluzzi, 1998; McQuiston and Katz, 2001; Hayar et al., 2004a). Newly generated, retrovirus-labeled interneurons exhibiting larger EPSC amplitudes (up to $-240 \mathrm{pA}$ ) have also been observed, but more rarely (Belluzzi et al., 2003). The latter cells exhibit spontaneous EPSCs that can be blocked by kynurenate, indicating that the EPSCs are glutamatergic. Our results indicate that the mouse EPL interneurons also manifest large spontaneous glutamatergic EPSP/Cs, and further indicate that these EPSP/Cs are mediated by AMPA/kainate receptors. Because the frequency is greatly reduced in TTX, the 
EPSP/Cs of the EPL interneurons appear to be driven primarily by presynaptic action potentials.

Sixty percent (10/16) of the EPL interneurons exhibit relatively high $(\sim 100 \mathrm{~Hz})$ frequencies of spontaneous EPSCs, whereas the other $\sim 40 \%$ (six of 16 ) exhibit relatively low $(\sim 40 \mathrm{~Hz})$ EPSC frequencies. The low-frequency EPSCs also tend to occur in bursts. The wide range of the EPSC frequencies and bursting together suggest that the spontaneous excitatory synaptic inputs of the interneurons are from multiple $M / T$ cells. The response latency and large synaptic jitter in responses of the interneurons to ON stimulation are consistent with this view, and with anatomical studies showing the excitatory synaptic inputs of EPL interneurons are primarily from $\mathrm{M} / \mathrm{T}$ cell dendrites within the EPL (Toida et al., 1996). Because external tufted (ET) cells within the $\mathrm{GL}$ proper burst spontaneously at $\sim 3 \mathrm{~Hz}$ (Hayar et al., 2004a), and some ET cells extend dendrites and/or axons into the EPL (Macrides and Schneider, 1982; Hayar et al., 2004a), they could impose the EPSC bursts of the interneurons. Tufted cells of the EPL proper, which in our slices exhibited slower spike bursts at $\sim 0.5 \mathrm{~Hz}$, could also impose the EPSC bursts, however. Our observation that the $\sim 36 \mathrm{~Hz}$ mean EPSC frequency of the interneurons that exhibited bursts of EPSCs was similar to the $\sim 31 \mathrm{~Hz}$ mean frequency of action potentials in the tufted cell bursts is consistent with this view. Another source of the bursts could be subsets of mitral cells that project dendrites to the same glomerulus or to several adjacent glomeruli, which have been shown to exhibit correlated activity (Carlson et al., 2000; Schoppa and Westbrook, 2001, 2002).

The spontaneous EPSC bursts of EPL interneurons could therefore be a manifestation of network interactions involving several different $\mathrm{M} / \mathrm{T}$ cell types associated with the same glomerulus or with two relatively synchronous glomeruli. In this regard, it is noteworthy that the dendrites of the superficial interneurons bridge the EPL space below pairs of adjacent glomeruli (Fig. $1 \mathrm{~A}$ and $\mathrm{B}$ ), that the dendritic extent of both the superficial and deeper (Fig. 1D) interneurons is similar to the glomerulus diameter, and that the inhibition of tufted cells in the rat EPL has been shown to be strongest within two glomerular widths (Christie et al., 2001). The absence of significant clustering in the highfrequency EPSC trains suggests that some of the EPL interneurons instead receive $M / T$ cell inputs from adjacent or more widespread glomeruli that are relatively asynchronous, however, at least in slice preparations.

Our recordings from fluorescent cells in slices from GAD65-GFP transgenic mice provide evidence that the EPL interneurons are GABAergic, and therefore, presumably, inhibitory. Inhibition plays an important role in encoding characteristics of odor stimuli, both at the level of the glomeruli (see Duchamp-Viret et al., 1993; Stopfer et al., 1997; Christensen et al., 1998) and at the level of the EPL (Yokoi et al., 1995). In the sphinx moth, inhibition with an interglomerular origin enhances the synchronization of principal cells that innervate the same glomerulus (Lei et al., 2002). In the olfactory bulb, inhibition that originates at the level of the $G L$ provides $M / T$ cells with receptive fields that have an inhibitory surround (Luo and Katz, 2001;
Aungst et al., 2003). The GL appears to have a modular spatial topography for encoding features of odors, which originates with the termination of $\mathrm{ON}$ axons that express the same odor receptor in at most a few glomeruli located on the medial and lateral aspects of the bulb (Ressler et al., 1994; Vassar et al., 1994; Mombaerts et al., 1996) and results in the activation of different clusters of glomeruli by different molecular characteristics of odors, such as carbon chain length (Friedrich and Korsching, 1997; Belluscio and Katz, 2001; Leon and Johnson, 2003; Takahashi et al., 2004). The deeper layers of the olfactory bulb are also differentially activated by odors (Guthrie et al., 1993; Kauer and Cinelli, 1993). One function of the EPL interneurons could therefore be to inhibit the $M / T$ cells that innervate one glomerulus or several adjacent glomeruli in response to the excitation of other EPL interneurons by $\mathrm{M} / \mathrm{T}$ cells that innervate the same glomerulus or glomeruli. This inhibition could help with $M / T$ cell tuning in response to similar odors that activate adjacent glomeruli having overlapping receptive ranges (Takahashi et al., 2004) and/or in response to strong stimulus conditions that increase the numbers of responsive glomeruli (Rubin and Katz, 1999; Johnson and Leon, 2000; Spors and Grinvald, 2002).

The responses of single $\mathrm{M} / \mathrm{T}$ cells are complex, exhibiting periods of both excitation and inhibition (Meredith and Moulton, 1978; Hamilton and Kauer, 1989; Wellis et al., 1989) and pronounced decreases in response latency with increases in the odor concentration (Hamilton and Kauer, 1989; Cang and Isaacson, 2003). This complexity makes comparisons among different stimulation and recording conditions difficult, but there is nevertheless some indication that more mouse $\mathrm{M} / \mathrm{T}$ cells respond to high than low odor concentrations (Reinken and Schmidt, 1986). Shortlatency (3-10 ms) IPSPs that do not appear to originate from PG cells or granule cells have been observed in mouse mitral cells in response to stimulation of nearby $\mathrm{M} / \mathrm{T}$ cells (Urban and Sakmann, 2002). These IPSPs could originate from EPL interneurons. We postulate that the $E P L$ interneurons provide focal, interglomerular inhibition within the EPL that is related to several adjacent glomeruli. This study has provided an initial characterization of the these interneurons, which could help to define spatial domains for odor encoding at the second synaptic level of olfactory processing, in between the glomeruli and the deeper cellular layers of the olfactory bulb.

Acknowledgments-We thank Jason Aungst, Phil Heyward, Sergei Karnup, Stephanie Parrish-Aungst, and Adam Puche for technical assistance, Frank Margolis for the GAD65-GFP mice, Faith Scipio for genotyping, and Michael Shipley and the Department of Anatomy and Neurobiology for sabbatical leave support for K. A. Hamilton at the University of Maryland, Baltimore. Support contributed by NIH grants DC00347, DC03112, DC03195, DC06356, DC36940, and the Biomedical Research Foundation of Northwest Louisiana.

\section{REFERENCES}

Aungst JL, Heyward PM, Puche AC, Karnup SV, Hayar A, Szabo G, Shipley MT (2003) Centre-surround inhibition among olfactory glomeruli. Nature 426:623-629. 
Bailey MS, Shipley MT (1993) Astrocyte subtypes in the rat olfactory bulb: morphological heterogeneity and differential laminar distribution. J Comp Neurol 328:501-526.

Belluscio L, Katz LC (2001) Symmetry, stereotypy, and topography of odorant representations in mouse olfactory bulbs. J Neurosci 21:2113-2122.

Belluzzi O, Benedusi M, Ackman J, LoTurco JJ (2003) Electrophysiological differentiation of new neurons in the olfactory bulb. J Neurosci 23:10411-10418.

Belluzzi O, Puopolo M, Benedusi M, Kratskin I (2004) Selective neuroinhibitory effects of taurine in slices of rat main olfactory bulb. Neuroscience 124:929-944.

Berretta N, Paolucci E, Bernardi G, Mercuri NB (2001) Glutamate receptor stimulation induces a persistent rhythmicity of the GABAeric inputs to rat midbrain dopaminergic neurons. Eur J Neurosci 14:777-784.

Briñón JG, Alonso JR, Arévalo E, García-Ojeda E, Lara J, Aijón J (1992) Calbindin D-28K-positive neurons in the rat olfactory bulb. An immunohistochemical study. Cell Tissue Res 269:289-297.

Cang J, Isaacson JS (2003) In vivo whole-cell recording of odorevoked synaptic transmission in the rat olfactory bulb. J Neurosci 23:4108-4116.

Carlson GC, Shipley MT, Keller A (2000) Long-lasting depolarizations in mitral cells of the rat olfactory bulb. J Neurosci 20:2011-2021.

Christensen TA, Waldrop BR, Hildebrand JG (1998) Multitasking in the olfactory system: context-dependent responses to odors reveal dual GABA-regulated coding mechanisms in single olfactory projection neurons. J Neurosci 18:5999-6008.

Christie JM, Schoppa NE, Westbrook GL (2001) Tufted cell dendrodendritic inhibition in the olfactory bulb is dependent on NMDA receptor activity. J Neurophysiol 85:169-172.

Christie JM, Westbrook GL (2003) Regulation of backpropagating action potentials in mitral cell lateral dendrites by A-type potassium currents. J Neurophysiol 89:2466-2472.

Chu A, Galarreta M, Hestrin S (2003) Synaptic interactions of latespiking neocortical neurons in Layer 1. J Neurosci 23:96-102.

Doyle MW, Andresen MC (2001) Reliability of monosynaptic sensory transmission in brain stem neurons in vitro. J Neurophysiol 85: 2213-2223.

Duchamp-Viret P, Duchamp A, Chaput M (1993) GABAergic control of odor-induced activity in the frog olfactory bulb: electrophysiological study with picrotoxin and bicuculline. Neuroscience 53:111-120.

Erdélyi F, Sekerkova G, Katarova Z, Hájos N, Palhalmi J, Freund TF, Mugnaini E, Szabó G (2002) GAD65-GFP transgenic mice expressing GFP in the GABaergic nervous system. FENS Abstr 1:A011-AO13.

Ezeh PI, Wellis DP, Scott JW (1993) Organization of inhibition in the rat olfactory bulb external plexiform layer. J Neurophysiol 70: 263-274.

Friedrich RW, Korsching SI (1997) Combinatorial and chemotopic odorant coding in the zebrafish olfactory bulb visualized by optical imaging. Neuron 18:737-752.

Galarreta M, Erdélyi F, Szabó G, Hestrin S (2004) Electrical coupling among irregular-spiking GABAergic interneurons expressing cannabinoid receptors. J Neurosci 24:9770-9778.

Galarreta M, Hestrin S (2002) Electrical and chemical synapses among parvalbumin fast-spiking GABAergic interneurons in adult mouse neocortex. Proc Natl Acad Sci USA 99:12438-12443.

Gall C, Seroogy KB, Brecha N (1986) Distribution of VIP- and NPY-like immunoreactivities in rat main olfactory bulb. Brain Res 374 : 389-394.

Gerstein GL, Perkel DH (1972) Mutual temporal relationships among neuronal spike trains. Statistical techniques for display and analysis. Biophys J 12:453-473.

Getchell TV, Shepherd GM (1975) Short-axon cells in the olfactory bulb: dendrodendritic synaptic interactions. J Physiol (Lond) 251: 523-548.
Giustetto M, Bovolin P, Fasolo A, Bonino M, Cantino D, SassoèPognetto M (1997) Glutamate receptors in the olfactory bulb synaptic circuitry: heterogeneity and synaptic localization of $\mathrm{N}$-methylD-aspartate receptor subunit 1 and AMPA receptor subunit 1 . Neuroscience 76:787-798.

Guthrie KM, Anderson AJ, Leon M, Gall C (1993) Odor-induced increases in c-fos mRNA expression reveal an anatomical "unit" for odor processing in olfactory bulb. Proc Natl Acad Sci USA 90: 3329-3333.

Hamilton KA, Coppola DM (2003) Distribution of GluR1 is altered in the olfactory bulb following neonatal naris occlusion. J Neurobiol 54 : 326-336.

Hamilton KA, Kauer JS (1989) Patterns of intracellular potentials in salamander mitral/tufted cells in response to odor stimulation. J Neurophysiol 62:609-625.

Hayar A, Karnup S, Ennis M, Shipley MT (2004b) External tufted cells: a major excitatory element that coordinates glomerular activity. J Neurosci 24:6676-6685.

Hayar A, Karnup S, Shipley MT, Ennis M (2004a) Olfactory bulb glomeruli: external tufted cells intrinsically burst at theta frequency and are entrained by patterned olfactory input. J Neurosci 24 : 1190-1199.

Heyward P, Ennis M, Keller A, Shipley MT (2001) Membrane bistability in olfactory bulb mitral cells. J Neurosci 21:5311-5320.

Isaacson JS, Strowbridge BW (1998) Olfactory reciprocal synapses: dendritic signaling in the CNS. Neuron 20:749-761.

Jahr CE, Nicoll RA (1982) An intracellular analysis of dendrodendritic inhibition in the turtle in vitro olfactory bulb. J Physiol (Lond) 326:213-234.

Johnson BA, Leon M (2000) Modular representations of odorants in the glomerular layer of the rat olfactory bulb and the effects of stimulus concentration. J Comp Neurol 422:496-509.

Kauer JS, Cinelli AR, (1993) Are there structural and functional modules in the vertebrate olfactory bulb? Microsc Res Tech 24: 157-167.

Kawaguchi $Y$ (1993) Groupings of nonpyramidal and pyramidal cells with specific physiological and morphological characteristics in rat frontal cortex. J Neurophysiol 69:416-431.

Kawaguchi $Y$ (1995) Physiological subgroups of nonpyramidal cells with specific morphological characteristics in layer II/III of rat frontal cortex. J Neurosci 14:2638-2655.

Kawaguchi Y, Kubota Y (1993) Correlation of physiological subgroupings of nonpyramidal cells with parvalbumin- and calbindin ${ }_{\mathrm{D} 28 \mathrm{~K}}$-immunoreactive neurons in layer $\mathrm{V}$ of rat frontal cortex. J Neurophysiol 70:387-396.

Kawaguchi Y, Kubota Y (1997) GABAergic cell subtypes and their synaptic connections in rat frontal cortex. Cereb Cortex 7: $476-486$.

Kosaka K, Heizmann CW, Kosaka T (1994) Calcium-binding protein parvalbumin-immunoreactive neurons in the rat olfactory bulb. 1. Distribution and structural features in adult rat. Exp Brain Res 99:191-204

Kosaka K, Toida K, Aika Y, Kosaka T (1998) How simple is the organization of the olfactory glomerulus?: the heterogeneity of so-called periglomerular cells. Neurosci Res 30:101-110.

Kosaka T, Kosaka K, Heizmann CW, Nagatsu I, Wu J-Y, Yanaihara N, Hama K (1987) An aspect of the organization of the GABAergic system in the rat main olfactory bulb: laminar distribution of immunohistochemically defined subpopulations of GABAergic neurons. Brain Res 411:373-378.

Lei H, Christensen TA, Hildebrand JG (2002) Local inhibition modulates odor-evoked synchronization of glomerulus-specific output neurons. Nat Neurosci 5:557-565.

Leon M, Johnson B (2003) Olfactory coding in the mammalian olfactory bulb. Brain Res Rev 42:23-32.

Lowe $\mathrm{G}$ (2002) Inhibition of backpropagating action potentials in mitral cell secondary dendrites. J Neurophysiol 88:64-85. 
Luo M, Katz L (2001) Response correlation maps of neurons in the mammalian olfactory bulb. Neuron 32:1165-1179.

Macrides F, Schneider SP (1982) Laminar organization of mitral and tufted cells in the main olfactory bulb of the adult hamster. J Comp Neurol 208:419-430.

Mann-Metzer P, Yarom Y (1999) Electrotonic coupling interacts with intrinsic properties to generate synchronized activity in cerebellar networks of inhibitory interneurons. J Neurosci 19:3298-3306.

Margrie TW, Sakmann B, Urban NN (2001) Action potential propagation in mitral cell lateral dendrites is decremental and controls recurrent and lateral inhibition in the mammalian olfactory bulb. Proc Natl Acad Sci USA 98:319-324.

McGann JP, Moyer JR Jr, Brown TH (2001) Predominance of latespiking neurons in layer $\mathrm{VI}$ of rat perirhinal cortex. J Neurosci 21:4969-4976.

McQuiston AR, Katz LC (2001) Electrophysiology of interneurons in the glomerular layer of the rat olfactory bulb. J Neurophysiol 86:1899-1907.

Meredith M, Moulton DG (1978) Patterned response to odor in single neurones of goldfish olfactory bulb: influence of odor quality and other stimulus parameters. J Gen Physiol 71:615-643.

Mirich JM, Williams NC, Berlau DJ, Brunjes PC (2002) Comparative study of aging in the mouse olfactory bulb. J Comp Neurol 454: 361-372.

Mombaerts P, Wang F, Dulac C, Chao SK, Nemes A, Mendelsohn M, Edmondson J, Axel R (1996) Visualizing an olfactory sensory map. Cell 87:675-686.

Montague AA, Greer CA (1999) Differential distribution of ionotropic glutamate receptor subunits in the rat olfactory bulb. J Comp Neurol 405:233-246.

Mori K, Kishi K, Ojima H (1983) Distribution of dendrites of mitral, displaced mitral, tufted, and granule cells in the rabbit olfactory bulb. J Comp Neurol 219:339-355.

Orona E, Rainer EC, Scott JW (1984) Dendritic and axonal organization of mitral and tufted cells in the rat olfactory bulb. J Comp Neurol 226:346-356.

Petralia RS, Wenthold RJ (1992) Light and electron immunocytochemical localization of AMPA-selective glutamate receptors in the rat olfactory bulb. J Comp Neurol 318:329-354.

Philpot BD, Lim JH, Brunjes PC (1997) Activity-dependent regulation of calcium-binding proteins in the developing rat olfactory bulb. J Comp Neurol 387:12-26.

Pinching AF, Powell TPS (1971) The neuropil of the glomeruli of the olfactory bulb. J Cell Sci 9:347-377.

Price JL, Powell TPS (1970) The synaptology of the granule cells of the olfactory bulb. J Cell Sci 7:125-155.

Puopolo M, Belluzzi O (1998) Inhibitory synapses among interneurons in the glomerular layer of rat and frog olfactory bulbs. J Neurophysiol 80:344-349.

Reinken U, Schmidt U (1986) Reactions of olfactory bulb neurons to different stimulus intensities in laboratory mice. Exp Brain Res 63:151-157.

Ressler KJ, Sullivan SL, Buck LB (1994) Information coding in the olfactory system: evidence for a stereotyped and highly organized epitope map in the olfactory bulb. Cell 79:1245-1255.
Rubin BD, Katz LC (1999) Optical imaging of odorant representations in the mammalian olfactory bulb. Neuron 23:499-511.

Schneider SP, Macrides F (1978) Laminar distributions of interneurons in the main olfactory bulb of the adult hamster. Brain Res Bull 3:73-82.

Schneider SP, Scott JW (1983) Orthodromic responses properties of rat olfactory bulb mitral and tufted cells correlate with their projection patterns. J Neurophysiol 50:358-379.

Schoppa NE, Westbrook GL (2001) Glomerulus-specific synchronization of mitral cells in the olfactory bulb. Neuron 31:639-651.

Schoppa NE, Westbrook GL (2002) AMPA autoreceptors drive correlated spiking in olfactory bulb glomeruli. Nat Neurosci 5:11941202.

Scott JW, McDonald JK, Pemberton JL (1987) Short axon cells of the rat olfactory bulb display NADPH-diaphorase activity, neuropeptide Y-like immunoreactivity, and somatostatin-like immunoreactivity. J Comp Neurol 260:378-391.

Shepherd GM, Chen WR, Greer CA (2004) Olfactory bulb. In: The synaptic organization of the brain, 5th edition (GM Shepherd, ed), pp 165-216. New York: Oxford University Press.

Sokal RR, Rohlf FJ (1981) Biometry, 2nd edition, pp 58-60. San Francisco: W.H. Freeman and Co.

Spors H, Grinvald A (2002) Spatio-temporal dynamics of odor representations in the mammalian olfactory bulb. Neuron 34:301-315.

Stopfer M, Bhagavan S, Smith BH, Laurent G (1997) Impaired odour discrimination on desynchronization of odour-encoding neural assemblies. Nature 390:70-74.

Takahashi YK, Kurosaki M, Hirono S, Mori K (2004) Topographic representation of odorant molecular features in the rat olfactory bulb. J Neurophysiol 92:2413-2427.

Toida K, Kosaka K, Heizmann CW, Kosaka T (1996) Electron microscopic serial-sectioning/reconstruction study of parvalbumincontaining neurons in the external plexiform layer of the rat olfactory bulb. Neuroscience 72:449-466.

Urban NN, Sakmann B (2002) Reciprocal intraglomerular excitation and intra- and interglomerular lateral inhibition between mouse olfactory bulb mitral cells. J Physiol (Lond) 542:355-367.

Van Gehuchten A, Martin I (1891) Le bulbe olfactif chez quelques mammifères. Cellule 7:205-237.

Vassar R, Chao SK, Sitcheran R, Nuñez JM, Vosshall LB, Axel R (1994) Topographic organization of sensory projections to the olfactory bulb. Cell 79:981-991.

Wellis DP, Scott JW, Harrison TA (1989) Discrimination among odorants by single neurons of the rat olfactory bulb. J Neurophysiol 61:1161-1177.

Wellis DP, Scott JW (1990) Intracellular responses of identified rat olfactory bulb interneurons to electrical and odor stimulation. J Neurophysiol 64:932-947.

Xiong W, Chen WR (2002) Dynamic gating of spike propagation in the mitral cell lateral dendrites. Neuron 34:115-126.

Yokoi M, Mori K, Nakanishi S (1995) Refinement of odor molecule tuning by dendrodendritic synaptic inhibition in the olfactory bulb. Proc Natl Acad Sci USA 92:3371-3375. 